\title{
PENGARUH KOMPOSISI RESIN TERHADAP KEKUATAN MEKANIK PAPAN PARTIKEL YANG DIPERKUAT SERBUK KAYU AKASIA
}

\author{
Eko Nugroho, Asroni \\ Jurusan Teknik Mesin, Fakultas Teknik, Universitas Muhammadyah Metro Lampung \\ Jl. Ki Hajar Dewantara 15 A Metro, Lampung \\ Email : exonugros@yahoo.co.id, asroni@engineer.com
}

\begin{abstract}
Abstrak
Faktor yang mempengarui kualitas papan partikel antara lain adalah perekat dan serbuk kayu. Perekat dengan jenis resin merupakan perekat yang cukup kuat digunakan sebagai matrik pada papan partikel (Nuryawan,2009). Tujuan dari penelitian ini adalah untuk mendapatkan komposisi yang ideal antara resin dan serbuk kayu akasia sehingga didapatkan sifat mekanik berupa kekuatan tarik dan kekerasan yang optimum. Resin yang dipakai adalah polyester dengan variasi komposisi 40\%, 50\%, dan $60 \%$. Tahapan penelitian ini di mulai dengan pembuatan alat hotpress dan cetakan untuk pembuatan papan partikel. Kemudian papan partikel dengan variasi komposisi resin yang berjumlah 18 spesimen dibuat specimen uji sesuai standar ASTM. Dari penelitian yang telah dilakukan didapatkan hasil nilai kekerasan ratarata komposit papan partikel dengan komposisi resin 40\%, 50\%, dan $60 \%$ berturut turut adalah adalah 67.8 HRR, 40.2 HRR dan 56.4 HRR. Nilai kekerasan tertinggi didapat pada komposisi resin $40 \%$ dikarenakan kekuatan pada materialnya lebih merata atau homogen, sehingga menghasilkan komposit dengan nilai kekerasan yang baik. Pada komposisi resin 50\%, nilai kekerasannya terendah karena perekat terkonsentrasi pada satu daerah yang menyebabkan interface partikel dan perekat menjadi lemah, disamping itu perekat juga mempunyai sifat kristalin yang tinggi. Sedangkan dari hasil pengujian tarik didapatkan data pada komposisi resin $40 \%, 50 \%$, dan $60 \%$ bernilai 10,62 N/mm $20.76 \mathrm{~N} / \mathrm{mm}^{2}$, dan $8.195 \mathrm{~N} / \mathrm{mm}^{2}$. Dari hasil pengujian ini dapat disimpulkan bahwa nilai optimal didapat pada komposisi resin $40 \%$ baik kekerasan maupun uji tarik.
\end{abstract}

Kata kunci : Komposit, Papan Partikel, Resin, Kekerasan, Uji Tarik.

\section{PENDAHULUAN}

Papan partikel adalah papan yang dibuat dari partikel kayu atau bahan berlignoselulosa lainnya yang diikat dengan perekat organik atau sintesis dan dengan bantuan satu atau lebih unsur panas, tekanan, kelembaban, katalis dan lain-lain (Iskandar,2006). Proses pembuatan papan partikel adalah dengan mencampurkan bahan perekat seperti resin dengan partikel kayu seperti serbuk kayu kemudian ditekan dengan pemanasan.

Papan partikel banyak digunakan sebagai bahan baku furnitur, dekorasi dan konstruksi. Untuk itu diperlukan kualitas papan partikel yang baik yang dapat menjamin kekuatan papan partikel tersebut.

Salah satu faktor yang mempengaruhi kualitas papan partikel adalah perbandingan komposisi yang tepat antara perekat dan serbuk kayu sehingga 
diharapkan menghasilkan papan partikel yang berkualitas tinggi.

Dari pemaparan diatas sangat perlu dilakukan penelitian tentang komposisi perekat yang ideal yang akan menghasilkan kekuatan mekanik papan partikel yang paling optimal. Dalam penelitian ini perekat yang digunakan adalah jenis resin polyester sedangkan serbuk kayu didapatkan dari hasil gergaji kayu akasia.

\section{TINJAUAN PUSTAKA}

\section{Kayu Akasia}

Kayu Akasia (Acacia mangium Wild) adalah tanaman asli yang banyak tumbuh di wilayah Papua Nugini, Papua Barat dan Maluku. Tanaman ini pada mulanya dikembangkan di Malaysia Barat dan selanjutnya di Malaysia Timur, yaitu di Sabah dan Serawak.

Di Indonesia sejak dicanangkan pembangunan HTI pada tahun 1984, kayu Akasia telah dipilih sebagai salah satu jenis favorit untuk ditanam di areal HTI. Begitu juga di Propinsi Lampung, budi daya kayu akasia sangat meningkat tajam bahkan tidak hanya pada areal yang luas tetapi sudah dibudidayakan pada pekarang rumah.

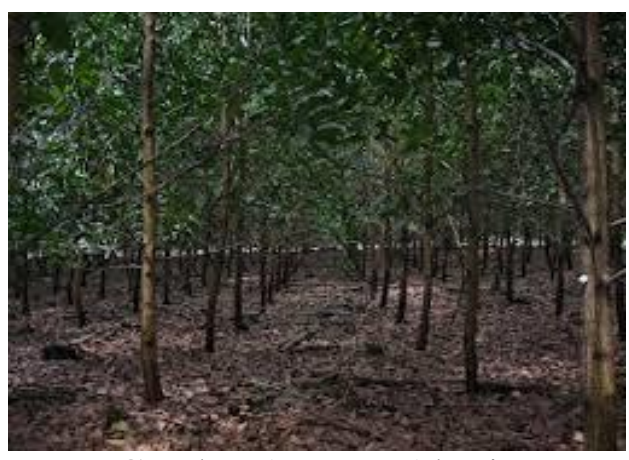

Gambar 1. Kayu Akasia

Berdasarkan sifat-sifat tersebut kayu mangium (Acacia mangium Wild.) memiliki sifat dan kelas ketahanan, keawetan dan keterawetan seperti tercantum dalam Tabel 1 dan 2.

Tabel 1. Ketahanan kayu Akasia terhadap rayap tanah dan penggerek di laut.

\begin{tabular}{|c|c|c|}
\hline Jenisserangan & Intensitassereangan & Kelaskethananan \\
\hline Ravaptanah (Macrotemes) & 55 (helotat) & IV \\
\hline Pengerered dil laut Pholadididare) & H(sedang) & III \\
\hline 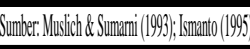 & & \\
\hline
\end{tabular}

Berdasarkan kelas keawetan Martawijaya \& Barly (1990) menyatakan bahwa kayu mangium memiliki sifat keawetan yang berbeda menurut asal kayunya. Kayu mangium dari hutan tanaman (asal Jawa Barat) relatif memiliki sifat keawetan lebih buruk (kelas awet II III) dibanding kayu mangium dari hutan alam (asal Maluku).

Tabel 2. Kelas awet dan keterawetan kayu Akasia menurut asal pohon

\begin{tabular}{|l|c|c|c|c|}
\hline \multirow{2}{*}{ Asal pohon } & \multicolumn{3}{|c|}{ Jenis jamur } & \multirow{2}{*}{$\begin{array}{c}\text { Penetrasi bahan } \\
\text { pengawet CCA }\end{array}$} \\
\cline { 2 - 4 } & A & B & C & penaw \\
\hline Hutan alam & $1,40^{*}(\mathrm{II})$ & $1,05^{*}(\mathrm{I})$ & $0,20^{*}(\mathrm{I})$ & $24,9(\mathrm{II})$ \\
\hline Hutan tanaman & $7,11^{*}(\mathrm{III})$ & $3,79^{*}(\mathrm{II})$ & $1,71^{*}(\mathrm{II})$ & $64,2(\mathrm{II})$ \\
\hline $\begin{array}{l}\text { Sumber: Martawijaya \& Barly }(1990) \\
\text { Keterangan: Jamur A = Schizophyllum commune, } \mathrm{B}=\text { Pynoporus sanguineus dan C }=\text { Dacryopinax } \\
\text { pathularia. Angka dalam kurung adalah kelas awet dan keterawetan. }\end{array}$ \\
\hline
\end{tabular}

\section{Papan Partikel}

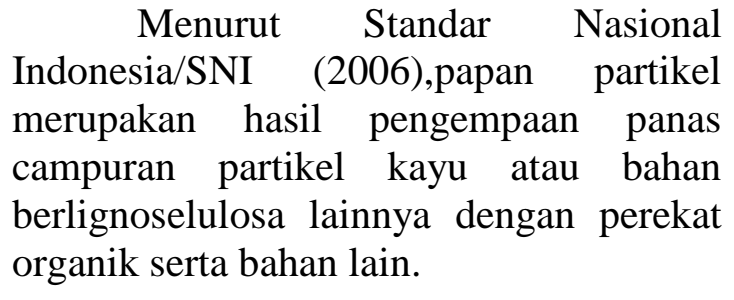

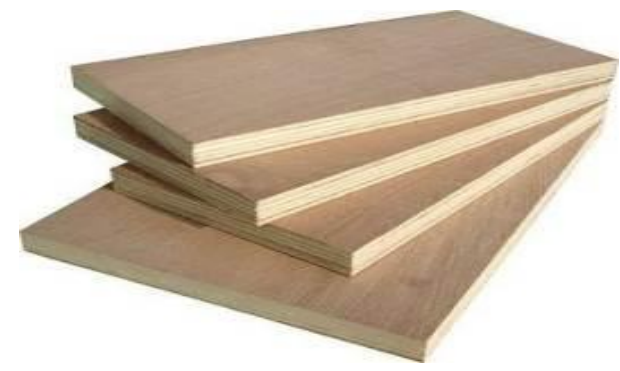

Gambar 2. Papan Partikel 
Komponen utama penyusun papan partikel adalah serbuk kayu dan perekat.

Menurut Wirsanto (2007: 13) "Serbuk gergaji kayu adalah suatu bahan baku kayu yang diolah dan dipotong dengan menggunakan alat (gergaji kayu) menjadi serbuk-serbuk kecil”.

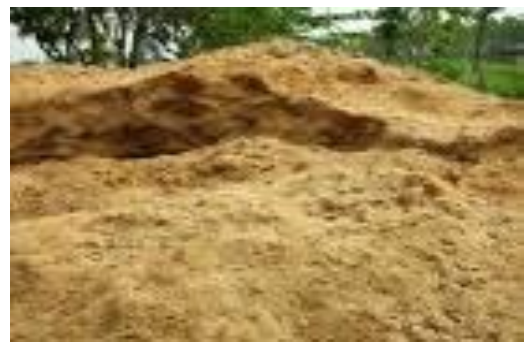

Gambar 3. Serbuk Kayu Akasia

Fungsi serbuk kayu dalam papan partikel adalah sebagai reinforcement atau penguat yang berfungsi untuk menahan beban utama.

Dalam pembuatan papan partikel perekat bertindak sebagai matrik yang berfungsi sebagai:

1. Mentransfer tegangan ke serat secara merata.

2. Melindungi serat dari gesekan mekanik.

3. Memegang dan mempertahankan serat pada posisinya.

4. Melindungi dari lingkungan yang merugikan.

Dalam penelitian ini, jenis matriks atau perekat yang dipilih adalah jenis Unsaturated Poliyester Resin dengan merek dagang YUKALAC 157 BQTN-EX dengan data teknis sebagai berikut:

1. Masa jenis $(\rho)=1,2 \mathrm{~g} / \mathrm{cm}^{3}$

2. Kekuatan tarik $(\sigma)=12,07 \mathrm{~N} / \mathrm{mm}^{2}$

3. Modulus elastisitas $(\mathrm{E})=1,18.103$ $\mathrm{N} / \mathrm{mm}^{2}$

4. Poisson ratio $(\mathrm{v})=0,33$

\section{Pengujian Mekanik}

Pengujian mekanik bertujuan untuk memperoleh karakteristik kekuatan mekanik suatu bahan.

1) Pengujian Tarik
Pengujian tarik adalah macam pengujian yang paling sering dilakukan pada suatu benda. Pada pengujian tarik akan didapatkan data berupa karakteristik mekanik seperti tegangan luluh, tegangan tarik, regangan, dan modulus elastisitas.

2) Pengujian Kekerasan

Prinsip pengujian kekerasan didasarkan pada kedalaman penetrasi dari indentor terhadap benda uji. Bila hasil penetrasi dari bahan dangkal, maka berarti bahan tersebut keras dan sebaliknya pada bahan yang lunak maka hasil penetrasinya makin dalam. Dalam penelitian ini pengujian kekerasan menggunakan alat uji kekerasan jenis Rockwell.

\section{METODE PENELITIAN}

\section{Waktu dan Tempat Penelitian}

Penelitian ini dilaksanakan di Laboratorium Terpadu Jurusan Teknik Mesin Fakultas Teknik Universitas Muhammadiyah Metro.

\section{Tahapan Pelaksanaan Penelitian}

Pelaksanaan penelitian dilakukan dalam beberapa tahapan seperti pembuatan alat hotpress, pembuatan papan partikel, pembuatan spesimen uji, pengujian tarik dan kekerasan, dan analisa data.

\section{Pembuatan Alat Hotpress}

Alat hotpress adalah alat yang digunakan untuk membuat papan partikel dengan cara penekanan dan pemanasan pada cetakan papan partikel.

\section{Pembuatan Papan Partikel}

1) Pembuatan Cetakan

Bahan yang digunakan untuk cetakan papan partikel ini adalah plat besi. Hal ini dimaksudkan agar cetakan mampu menahan tekanan tinggi. Selanjutnya cetakan dilapisi aluminium 
foil untuk mempermudah pelepasan papan partikel dari cetakan .

2) Pembuatan Papan Partikel

Adapun tahap pembuatan papan partikel ini adalah sebagai berikut:

a. Partikel dibuat dari serbuk gergaji limbah kayu akasia dengan ukuran 20 mess.

b. Cetakan dibersihkan, kemudian di lapisi alumunium foil dan oli secara merata agar komposit tidak menempel pada cetakan

c. Pencampuran partikel dengan perekat resin polyester dengan perbandingan komposisi resin dan serbuk kayu yang sudah ditentukan kemudian dicampur hingga homogen.

d. Campuran yang homogen kemudian di tuang kedalam cetakan dan diratakan.

e. Setelah itu dilakukan penekanan dan pemanasan dengan alat hotpress dengan tekanan $10 \mathrm{~kg} / \mathrm{cm}^{2}$ dan suhu $150{ }^{0} \mathrm{C}$ selama 15 menit.

f. Sebelum dilakukan pengujian, dilakukan proses pengkondisian selama 2 minggu, agar papan partikel kering secara maksimal. Setelah itu papan partikel dipotong untuk membuat specimen uji.

\section{Pembuatan spesimen uji}

Spesimen uji dibuat satu persatu sebanyak 18 buah dengan perincian 15 buah untuk uji tarik dan 3 buah untuk uji kekerasan. Adapun standar pengujian yang dilakukan adalah ASTM yaitu uji tarik menggunakan standar ASTM D 638 - 03 dan uji kekerasan menggunakan standar ASTM D 18 - 08 .

\section{Pengujian Specimen Uji.}

1. Pengujian tarik.

Pengujian tarik dilakukan di Lab.

Teknik Mesin UM Metro menggunakan mesin uji tarik berstandar ASTM. Hasil dari pengujian ini akan didapatkan data mengenai kekuatan tarik maksimum, kekuatan luluh, dan modulus elastisitas dari papan partikel.

2. Pengujian kekerasan

Pengujian kekerasan dilakukan di

Lab Teknik Mesin UM Metro menggunakan mesin uji keras Rockweel dengan skala indentor tipe R. Hasil dari uji kekerasan ini akan didapat nilai kekerasan dari papan partikel tersebut.

\section{Pengolahan Data dan Analisa Data}

Dari hasil pengujian akan didapatkan data berupa nilai kekuatan tarik dan kekerasan dari tiap specimen. Kemudian data tersebut akan dianalisa sehingga akan didapatkan specimen papan partikel yang mempunyai kekuatan tarik tertinggi dan kekerasan tertinggi.

\section{Alat dan Bahan yang Digunakan}
Alat
1. Saringan Serbuk Kayu mesh 20
2. Stopwatch
3. Alat hotpress
4. Cetakan
5. Alat uji tarik
6. Alat uji kekerasan

\section{Bahan}

1. Serbuk Kayu Akasia

2. Resin Polyester YUKALAC 157 BQTN-EX

3. Katalis MEKPO 


\section{Diagram Alir Penelitian.}

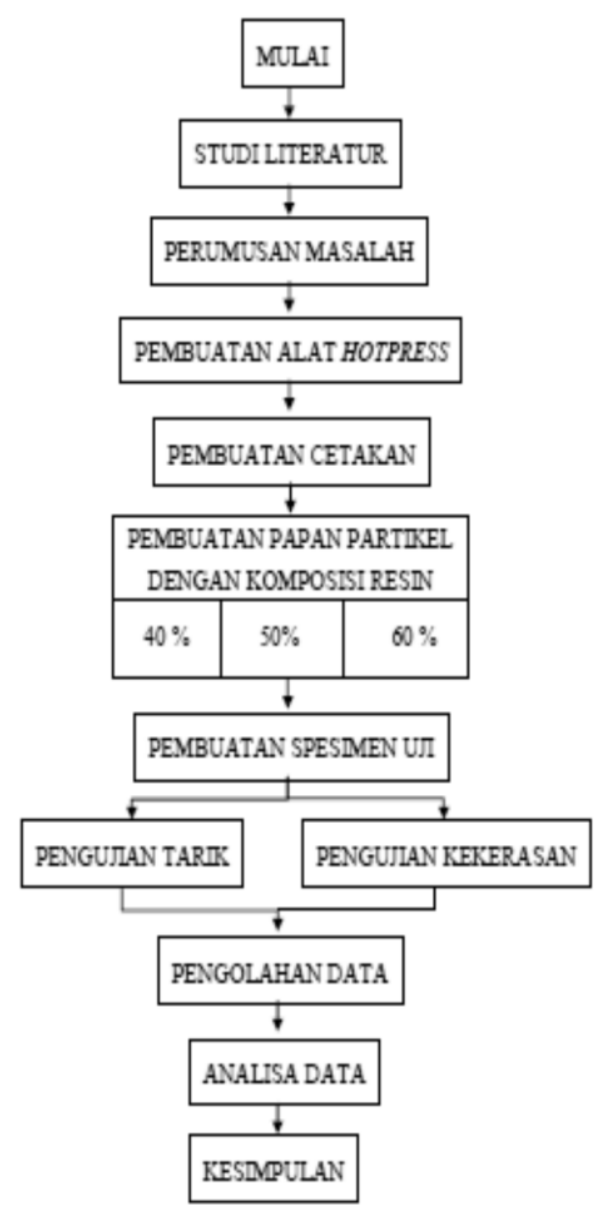

Gambar 4. Diagram Alir Penelitian

\section{HASIL DAN PEMBAHASAN}

\section{Pembuatan Alat Hotpress}

Proses perancangan dan pembuatan mesin hotpress komposit papan partikel dilakukan dengan ukuran dan bahan kontruksi yang ditentukan agar bisa digunakan dengan efesien.

\section{Data Lapangan}

Tabel 3. Data spesifikasi hotpress

\begin{tabular}{|c|l|c|c|}
\hline No & \multicolumn{1}{|c|}{ Nama } & Nilai & Satuan \\
\hline 1 & Luas penampang penyangga pencetak & 120000 & $\mathrm{~mm}^{2}$ \\
3 & Luas penampang penyangga penekan $\left(A_{b}\right)$ & 120000 & $\mathrm{~mm}^{2}$ \\
4 & Luas penampang penekan & 12000 & $\mathrm{~mm}^{2}$ \\
5 & Diameter tabung fluida & 7 & $\mathrm{~cm}$ \\
6 & Tekanan maksimal kompor listrik & 269 & ${ }^{0} \mathrm{C}$ \\
7 & Volume pencetak komposit & 207,98 & $\mathrm{~cm}^{2}$ \\
8 & Diameter baut & 180 & $\mathrm{~cm}^{3}$ \\
9 & Panjang baut & 17 & $\mathrm{~mm}$ \\
10 & Panjang plat H untuk tiang & 70 & $\mathrm{~mm}$ \\
11 & Panjang plat H untuk penyangga tiang & $60(4$ buah $)$ & $\mathrm{cm}$ \\
12 & Panjang plat H untuk penyangga tiang & $30(2 \mathrm{buah})$ & $\mathrm{cm}$ \\
\hline
\end{tabular}

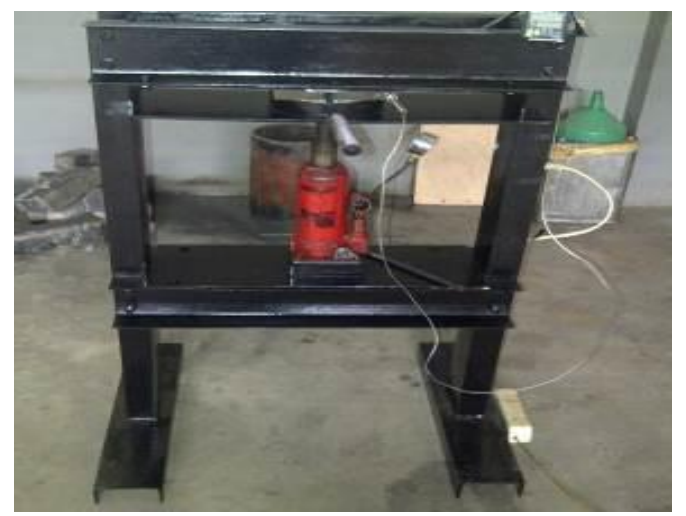

Gambar 5. Mesin hotpress komposit papan partikel

\section{Pembuatan Cetakan}

Cetakan di buat dari plat baja dengan ketebalan $5 \mathrm{~mm}$ yang dibagi menjadi 2 jenis. Bagian pertama merupakan cetakan untuk spesimen uji tarik dan bagian lainnya untuk cetakan uji kekerasan. Banyaknya cetakan untuk uji tarik dibuat 5 buah dan uji kekeran dibuat 2 buah. Gambar cetakan uji tarik dan kekerasan dapat dilihat pada ini : 


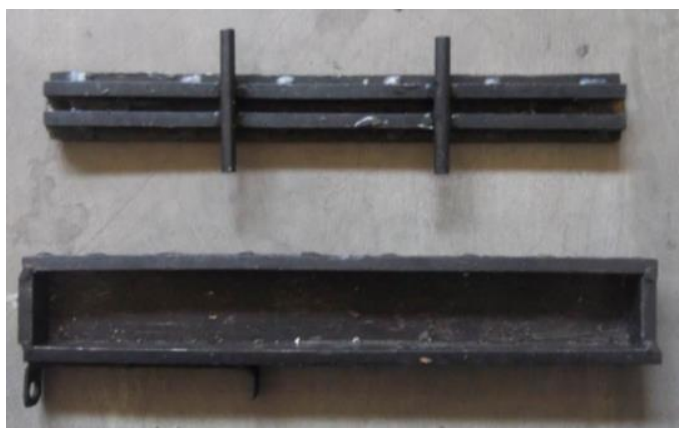

Gambar 6. Cetakan Uji Tarik

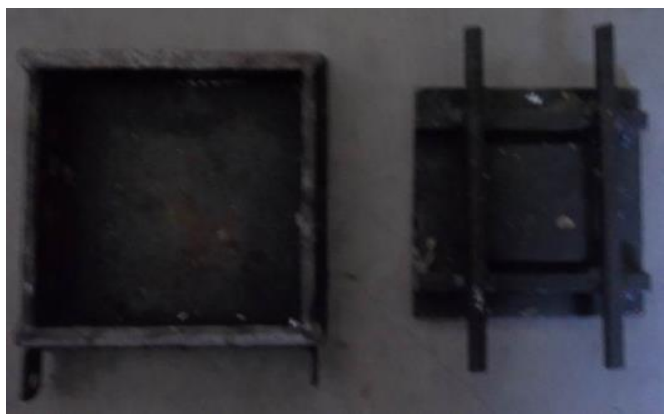

Gambar 7. Cetakan Uji Kekerasan

\section{Pembuatan Spesimen Uji}

Tahap selanjutnya adalah pembuatan spesimen uji dengan urutan sebagai berikut :

a. Partikel dibuat dari Serbuk gergaji limbah kayu akasia di ayak dengan ukuran 20 mess.

b. Penimbangan serbuk gergaji untuk mendapatkan perbandingan campuran antara resin dan serbuk gergaji menggunakan timbangan digital.

c. Cetakan dibersihkan, kemudian di lapisi alumunium foil dan oli secara merata agar komposit tidak menempel pada cetakan

d. Pencampuran partikel dengan perekat resin polyester dengan perbandingan komposisi resin dan serbuk kayu yang sudah ditentukan kemudian dicampur hingga homogen.

e. Campuran yang homogen kemudian di tuang kedalam cetakan dan diratakan.

f. Setelah itu dilakukan penekanan dan pemanasan dengan alat hotpress dengan tekanan $10 \mathrm{~kg} / \mathrm{cm}^{2}$ dan suhu $150{ }^{\circ} \mathrm{C}$ selama 15 menit.

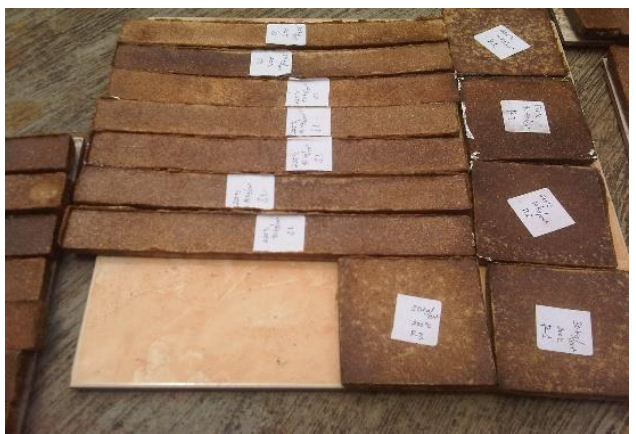

Gambar 8. Spesimen uji

\section{Pengujian Kekerasan Spesimen}

Pengujian ini menggunakan metode pengujian kekerasan rockwell. Dengan metode uji ASTM E 18-08 sehingga didapatkan hasil pada tabel 4 .

Tabel 4. Data Uji kekerasan rockwell

\begin{tabular}{|c|c|c|c|}
\hline $\begin{array}{l}\text { Ukuran partikel } \\
\quad(\text { Mesh })\end{array}$ & Komposisi Resin & Kekerasan (HRR) & $\begin{array}{c}\text { Nilai Kekerasan } \\
(H R R)\end{array}$ \\
\hline \multirow{5}{*}{ Mesh 20} & \multirow{5}{*}{$40 \%$} & 72 & \multirow{5}{*}{67.8} \\
\hline & & 68 & \\
\hline & & 69 & \\
\hline & & 55 & \\
\hline & & 75 & \\
\hline \multirow{5}{*}{ Mesh 20} & \multirow{5}{*}{$50 \%$} & 37 & \multirow{5}{*}{40.2} \\
\hline & & 58 & \\
\hline & & 22 & \\
\hline & & 39 & \\
\hline & & 45 & \\
\hline \multirow{5}{*}{ Mesh 20} & \multirow{5}{*}{$60 \%$} & 58 & \multirow{5}{*}{56.4} \\
\hline & & 65 & \\
\hline & & 55 & \\
\hline & & 48 & \\
\hline & & 56 & \\
\hline
\end{tabular}

Perbandingan nilai kekerasan ratarata dari data diatas dapat dilihat pada gambar 9 .

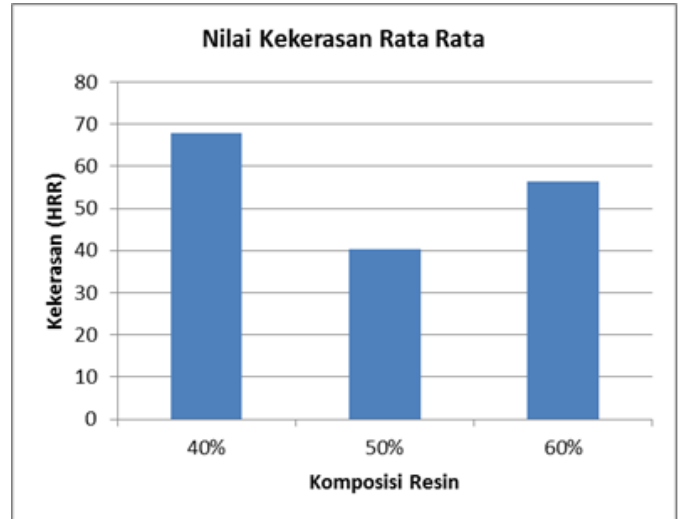

Gambar 9. Perbandingan Nilai Kekerasan 


\section{Pengujian Tarik Spesimen}

Pengujian selanjutnya adalah uji tarik dimana spesmen uji yang telah dibuat di beri beban tarik sampai putus sehingga diperoleh nilai uji tarik. Hasil tabel di bawah ini

Tabel 5. Data pengujian tarik

\begin{tabular}{|c|c|c|c|}
\hline $\begin{array}{c}\text { Ukuran } \\
\text { partikel } \\
(\text { Mesh })\end{array}$ & Komposit Partikel & Stress $\left(\mathrm{N} / \mathrm{mm}^{2}\right)$ & $\begin{array}{l}\text { Rata-rata } \\
\left(\mathrm{N} / \mathrm{mm}^{2}\right)\end{array}$ \\
\hline \multirow{3}{*}{ Mesh 20} & \multirow{3}{*}{$40 \%$} & 6,3873 & \multirow{3}{*}{10,614} \\
\hline & & 15,325 & \\
\hline & & 10,128 & \\
\hline \multirow{3}{*}{ Mesh 20} & \multirow{3}{*}{$50 \%$} & 0,6386 & \multirow{3}{*}{0,7613} \\
\hline & & 0,7485 & \\
\hline & & 0,8968 & \\
\hline \multirow{3}{*}{ Mesh 20} & \multirow{3}{*}{$60 \%$} & 10,892 & \multirow{3}{*}{8,195} \\
\hline & & 7,4741 & \\
\hline & & 6,2196 & \\
\hline
\end{tabular}

Perbandingan nilai kekuatan tarik papan partikel dari serbuk kayu akasia dapat dilihat pada gambar 10 di bawah ini.

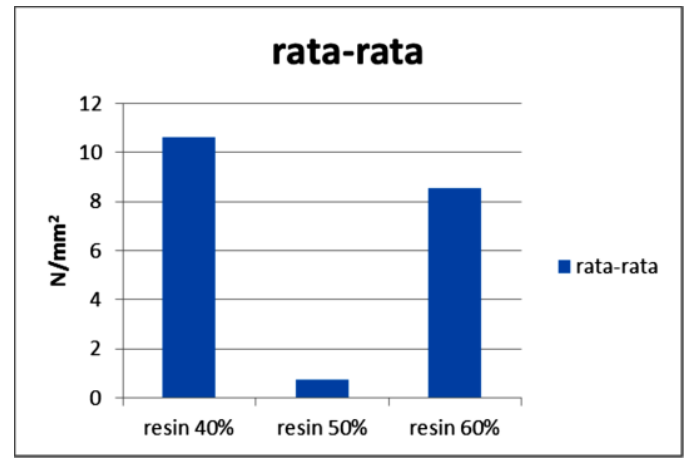

Gambar 10. Grafik rata-rata uji tarik

\section{Pembahasan}

Dari hasil penjelasan data diatas diperoleh nilai uji kekerasan komposit $40 \%, 50 \%$ dan $60 \%$ yaitu sebesar 67,8 $H R R, 40,2 H R R$ dan $56.4 H R R$ Nilai kekerasan komposit partikel kayu akasia untuk komposit $50 \%$ untuk nilainya terendah disebabkan perekat terkonsentrasi pada satu daerah yang menyebabkan interface partikel dan perekat menjadi lemah, disamping itu perekat juga mempunyai sifat kristalin yang tinggi. Sedangkan untuk komposit
60\% sebesar 56.4 HRR mengalami peningkatan yang kurang baik dikarenakan fraksi massa lebih rendah dibandingkan dengan perekat. Sehingga menghasilkan komposit partikel yang kurang baik kemudian untuk komposit $40 \%$ sebesar 67.8 HRR diperoleh nilai kekerasan tertinggi dikarena kekuatan pada materialnya lebih merata atau homogen, sehingga menghasilkan komposit dengan nilai kekerasan yang baik.

Sedangkan untuk hasil pengujian tarik yang didapat maka dapat disimpulakan bahwa komposit 40\%, 50\%, dan 60\% yaitu sebesar $10,62 \mathrm{~N} / \mathrm{mm} 2, \quad 0.76 \mathrm{~N} / \mathrm{mm}^{2}$ dan $8.195 \mathrm{~N} / \mathrm{mm}^{2}$ hal ini menyatakan bahwa pada komposit $50 \%$ memiliki nilai kuat terendah yaitu $0.76 \mathrm{~N} / \mathrm{mm}^{2}$ dikarenakan pada waktu pengepresan kurang maksimal sehingga kerapatan partikel dan matrik rendah, sehingga daya ikat partikel sebagai penguat juga rendah hal ini juga bisa disebabkan ikatan antar partikel yang kurang kuat menyebabkan mudah tergesernya bahan penguat didalam matrik komposit diakibatkan adanya gaya dari luar permukaan komposit. Pada komposit $40 \%$ dan $60 \%$ mengalami peningkatan nilai kuat tarik sebesar $10,62 \mathrm{~N} / \mathrm{mm}^{2}$ dan $8.195 \mathrm{~N} / \mathrm{mm}^{2}$. Dikarena kekuatan pada materialnya lebih merata atau lebih homogen, hal ini disebabkan adanya hubungan yang saling mendukung antara bahan penguat dan matrik dari komposit yang menyebabkan adanya ikatan yang kuat.

\section{KESIMPULAN DAN SARAN}

\section{Kesimpulan}

Dari penelitian awal yang telah dilakukan disimpulkan bahwa:

1. Nilai kekerasan rata- rata komposit papan partikel dengan komposisi resin 40\%, 50\%, dan $60 \%$ berturut turut adalah adalah 67.8 HRR, 40.2 HRR dan 56.4 HRR. Nilai kekerasan tertinggi didapat pada komposisi resin $40 \%$ dikarenakan kekuatan pada 
materialnya lebih merata atau homogen, sehingga menghasilkan komposit dengan nilai kekerasan yang baik. Pada komposisi resin 50\%, nilai kekerasannya terendah karena perekat terkonsentrasi pada satu daerah yang menyebabkan interface partikel dan perekat menjadi lemah, disamping itu perekat juga mempunyai sifat kristalin yang tinggi.

2. Dari hasil pengujian tarik yang didapat nilai kekuatan tarik dari variasi komposisi resin 40\%, 50\%, dan $60 \%$ yaitu sebesar $10,62 \mathrm{~N} / \mathrm{mm} 2,0.76 \mathrm{~N} / \mathrm{mm}^{2}$ dan $8.195 \mathrm{~N} / \mathrm{mm}^{2}$. Komposisi resin $50 \%$ memiliki nilai kuat terendah dikarenakan pada waktu pengepresan kurang maksimal sehingga kerapatan partikel dan matrik rendah. Nilai kekuatan tarik yang tertinggi didapat pada komposisi resin $40 \%$ dikarena kekuatan pada materialnya lebih merata atau lebih homogen, hal ini disebabkan adanya hubungan yang saling mendukung antara bahan penguat dan matrik dari komposit yang menyebabkan adanya ikatan yang kuat.

3. Dari hasil pengujian kekerasan dan uji tarik didapatkan komposisi resin $40 \%$ adalah yang paling optimal dibandingkan komposisi $50 \%$ dan $60 \%$.

\section{Saran}

Saran yang dapat disampaikan dari penelitian awal ini adalah :

1. Faktor pengadukan campuran resin perlu diperhatikan supaya adonan benar - benar homogen.

2. Penuangan komposit kedalam cetakan harus merata dan mencegah jangan sampai ada udara yang terjebak dalam cetakan.

\section{DAFTAR PUSTAKA}

Abdurachman \& Hadjib, N. 2006. Pemanfaatan kayu hutan rakyat untuk komponen bangunan.
Prosiding Seminar Hasil Litbang Hasil Hutan. Hal. 130-148.

Mujtahid, 2010. Pengaruh Ukuran Serbuk Aren Terhadap Kekuatan Bending, Densitas Dan Hambatan Panas Komposit Semen-Serbuk Aren (Arenga Pinnata). Teknik Mesin, Universitas Sebelas Maret Surakarta..

Muhdi.,Risnasari, I dan Putri, L.a. 2013, Upaya pemanfaatan limbah pemanen kayu akasia menjadi papan partikel. Bionatura-Jurnal Ilmu-ilmu Hayati dan Fisik Vol. 15, No. 1, Maret 2013: ISSN 1411 $-0903$

Nuryawan A, Massijaya MY, Hadi YS. 2008. Sifat Fisis dan Mekanis Oriented Strands Board (OSB) dari Akasia, Ekaliptus dan Gmelina Berdiameter Kecil: Pengaruh Jenis Kayu dan Macam Aplikasi Perekat. Jurnal Ilmu dan Teknologi Hasil Hutan 1(2): 6066

SNI. 1996. Mutu Papan Partikel. SNI 032105-1996.Dewan Standarisasi Nasional (DSN). Jakarta.

Tinambunan, D. 2001. Pemborosan Kayu Dalam Pemanenan Hutan Alam di Luar Pulau Jawa dan Upaya Mengatasinya. Buletin Hasil Hutan, Vol. 2 (1).

Tsoumis, G. 1991. Science and Technology Wood. Structure, Properties, Utilization. Van Vonstrand Reinhold Inc. USA. Walker, J.C.F. 1993. Primary Wood Processing Principles

Wijaya \& Dedi Dendi. 2011. Pengaruh Kadar Perekat dan Kombinasi Kayu Terhadap Sifat Fisis 
Mekanis OSB Ukuran Kecil dan

Besar dari Dua Jenis Kayu

Rakyat. Thesis. IPB. Bogor

Walker, J.C.F. 1993. Primary Wood Processing Principles and Practice. Published by Chapman \& Hall. London.

Widodo, B., 2008, Analisa Sifat Mekanik Komposit Epoksi Dengan Penguat Serat Pohon Aren (Ijuk) Model Lamina Berorientasi Sudut Acak (Random). Jurusan Teknik Mesin, ITN Malang

Wirsanto. 2007. Pemanfaatan Langsung Serbuk Kulit Kayu Akasia Sebagai Perekat Papan Partikel, Jurnal Ilmu dan Teknologi Kayu Tropis. Vol. 1, No. 1. 